\title{
A língua brasileira de sinais na formação dos profissionais de Enfermagem, Fisioterapia e Odontologia no estado da Paraíba, Brasil
}

\author{
Yanik Carla Araújo de Oliveira ${ }^{1}$ \\ Gabriela Maria Cavalcanti Costa ${ }^{2}$ \\ Alexsandro Silva Coura ${ }^{3}$ \\ Renata de Oliveira Cartaxo 4 \\ Inacia Sátiro Xavier de França ${ }^{5}$
}

OLIVEIRA, Y.C.A. et al. Brazilian sign language in the training of nursing, physiotherapy and dentistry professionals in the state of Paraíba, Brazil. Interface - Comunic., Saude, Educ., v.16, n.43, p.995-1008, out./dez. 2012.

The aim was to analyze the pedagogical projects for undergraduate nursing, physiotherapy and dentistry courses regarding inclusion of Brazilian sign language and the parameters that guide this educational action in professional training, in order to ensure comprehensiveness and humanization of care. This was a cross-sectional study on documents, with a qualitative approach, conducted on 25 courses in Paraíba, Brazil. The pedagogical projects of the courses were analyzed, and 24 course coordinators answered a questionnaire. The data were analyzed in accordance with Bardin. The results indicated that $58 \%$ of the courses offered Brazilian sign language, but that it was unavailable in teacher training courses. The course content covered topics such as the deaf community's culture, sign language and its linguistic structure, practical approaches to communication and inclusive policies and legislation. However, this reality existed alongside imprecise responses regarding organization of this component and professional education in sign language and its attributions.

Keywords: Sign language. Health human resource training. Nursing. Dentistry. Physiotherapy.
Objetivou-se analisar os projetos pedagógicos de cursos de graduação em Enfermagem, Fisioterapia e Odontologia, quanto à inclusão do componente Libras e aos parâmetros que norteiam esta ação educativa na formação dos profissionais, para assegurar a integralidade e humanização da assistência. Trata-se de estudo transversal e documental com abordagem qualitativa, realizado em 25 cursos da Paraíba, Brasil. Foram analisados os projetos pedagógicos dos cursos e 24 coordenadores responderam um questionário, sendo esses dados analisados à luz de Bardin. Os resultados indicam que $58 \%$ dos cursos oferecem a Libras e que os de licenciatura não a disponibilizam. Os conteúdos das ementas abordam temas como: a cultura da comunidade surda, a Libras e sua estrutura linguística, a abordagem prática de comunicação, política e legislações inclusivas. Porém, essa realidade segue paralela a respostas imprecisas no tocante à organização do componente, formação do profissional em Libras e suas atribuições.

Palavras-chave: Linguagem de sinais. Capacitação de recursos humanos em saúde. Enfermagem. Odontologia. Fisioterapia.

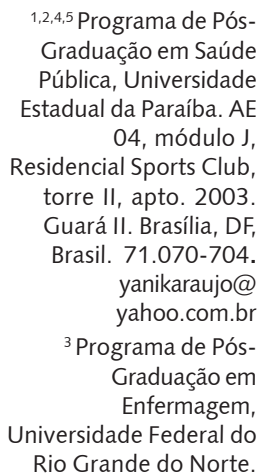
Enfermagem Rio Grande do Norte. 


\section{Introdução}

No Brasil, a preocupação com a inclusão social dos grupos vulneráveis passou a ser consistente no final do século passado. Dentre esses grupos, as pessoas com algum tipo de deficiência enfrentam dificuldade para realizar algumas atividades da vida diária e para usufruir de bens e serviços de saúde (Souza, Porrozzi, 2009).

Um tipo de deficiência que causa muitas adversidades no processo de socialização é a limitação auditiva (Souza, Porrozzi, 2009). A pessoa surda vivencia um grave problema sensorial que resulta em dificuldade de comunicação através da linguagem oral tradicional, gerando a necessidade do desenvolvimento de habilidades em outro canal de expressão, como a Língua Brasileira de Sinais (Libras) (Quadros, 2004). Essas pessoas formam, linguística e culturalmente, um grupo minoritário, no entanto, grande parte dos cursos de saúde desconsidera essa faceta social, enfocando a deficiência auditiva apenas no âmbito da patologia (Chaveiro, Barbosa, Porto, 2008).

O censo demográfico brasileiro realizado em 2010 contabilizou 5.735 .099 pessoas com problemas relacionados à perda auditiva. Esse fato chama a atenção para a necessidade do desenvolvimento de estratégias que assegurem a comunicação do surdo com a sociedade plural e, em especial, com os profissionais de saúde. Isto porque, quando os surdos procuram os serviços de saúde, se deparam com condições que interferem de maneira negativa na qualidade do processo de comunicação e, consequentemente, na assistência prestada (Oliveira, Lopes, Pinto, 2009).

$\mathrm{Na}$ tentativa de atender às demandas das pessoas com deficiência auditiva, o Estado sancionou a Lei no 10.436/2002, que reconhece a Libras como sistema linguístico da comunidade surda brasileira (Brasil, 2002c), e o Decreto no 5.626/2005 que estabeleceu

Art 3ㅇ A Libras deve ser inserida como disciplina curricular obrigatória nos cursos de formação de professores para o exercício do magistério, em nível médio e superior, e nos cursos de Fonoaudiologia, de instituições de ensino, públicas e privadas, do sistema federal de ensino e dos sistemas de ensino dos Estados, do Distrito Federal e dos Municípios. § 2- A Libras constituir-se-á em disciplina curricular optativa nos demais cursos de educação superior e na educação profissional, a partir de um ano da publicação deste Decreto. (Brasil, 2005, p.1)

O Conselho Nacional de Educação (CNE) e as Diretrizes Curriculares Nacionais dos Cursos (DCNs) de Graduação em Enfermagem, Fisioterapia e Odontologia elencam as recomendações a serem observadas na organização curricular das Instituições do Sistema de Educação Superior do país, objetivando garantir os conhecimentos gerais e específicos requeridos para o exercício da profissão com competências e habilidades.

Apesar de tais recomendações não citarem diretamente a Libras, mencionam que o projeto pedagógico deve formar um profissional dotado dos conhecimentos requeridos para o exercício das competências e habilidades gerais, dentre elas a comunicação. Além disso, as recomendações do CNE e as DCNs objetivam garantir uma formação que atenda às necessidades sociais da saúde, com ênfase no Sistema Único de Saúde (SUS), assegurando a integralidade e humanização da assistência (Brasil, 2002a, 2002b, 2001), tendo em vista que o processo comunicacional é "um dos desafios enfrentados na humanização em saúde" (Deslandes, Mitre, 2009, p.641).

De acordo com Sacristán (2000), um currículo é um conjunto de conteúdos teóricos e práticos selecionados, e criteriosamente organizados, para promover o desenvolvimento de habilidades e competências intelectuais e profissionais nos alunos. Esse processo deve ser permanente e estimular a autonomia dos discentes, considerando as demandas e necessidades prevalentes no processo saúde/ doença do cidadão, da família e da comunidade. Logo, a matriz curricular precisa estar integrada à realidade epidemiológica e profissional da região e do país, contribuindo para a integralidade das ações do cuidar.

Nessa perspectiva, se tem em vista a considerável prevalência de pessoas surdas no Brasil, em especial na Paraíba, que se apresenta em segundo lugar no ranking dos estados com a maior proporção 
de indivíduos com deficiência, com mais de 48 mil pessoas tendo relatado grande dificuldade ou incapacidade de ouvir (IBGE, 2010). Portanto, torna-se necessária a discussão sobre o oferecimento da Libras aos estudantes de graduação da área de saúde, sendo a justificativa para tal necessidade de ordem epidemiológica.

Destarte, selecionou-se o objeto "inserção da Libras no projeto pedagógico dos cursos da área de saúde", com apoio nas seguintes indagações: As Instituições de Ensino Superior (IES) já inseriram a Libras na matriz curricular das graduações em Enfermagem, Fisioterapia e Odontologia? Se já inseriram, que parâmetros norteiam esse componente na perspectiva da integralidade e humanização da assistência?

A comunicação efetiva, por meio do uso adequado das técnicas da comunicação interpessoal, é condição imprescindível para que o profissional, especialmente o enfermeiro, possa ajudar o paciente a atender suas demandas em saúde (Silva, 2006). O estudo se justifica pela lacuna de investigações relacionadas com as dificuldades do surdo para acessar os serviços de saúde devido às barreiras da comunicação. E, também, pela valorização do processo de ensino-aprendizagem da Libras, com o objetivo de formar recursos humanos capacitados a proverem o cuidado humanístico aos surdos.

Nessa perspectiva, este estudo pretendeu analisar se, nos projetos pedagógicos dos cursos de graduação em Enfermagem, Fisioterapia e Odontologia, está incluso o componente Libras na matriz curricular, e quais parâmetros norteiam esta ação educativa na formação dos profissionais, com vistas a assegurar a integralidade e humanização da assistência.

\section{Metodologia}

Trata-se de um estudo transversal com abordagem qualitativa, realizado no período de novembro de 2010 a junho de 2011, em IES localizadas no Estado da Paraíba e credenciadas pelo Ministério da Educação (MEC), que oferecem cursos de graduação em Enfermagem, Fisioterapia e Odontologia.

Para o levantamento dessas IES, foi acessado o site http://emec.mec.gov.br/, do Instituto Nacional de Estudos e Pesquisas Educacionais Anísio Teixeira (INEP). Identificaram-se 16 cursos de Enfermagem, dez de Fisioterapia e quatro de Odontologia, distribuídos em trinta IES localizadas em quatro cidades do estado: João Pessoa, Campina Grande, Patos e Cajazeiras.

Utilizou-se um diário de campo, em todas as fases da pesquisa, para anotação de observações e possíveis intercorrências. Primeiramente, realizou-se análise documental para averiguar quais projetos pedagógicos dessas IES ofereciam a Libras como componente da matriz curricular dos cursos selecionados.

Após a identificação dos 24 projetos pedagógicos com resultado positivo para a oferta da Libras, procedeu-se o acesso à ementa desse componente curricular em cada projeto, com vistas à elaboração de um questionário composto por questões abertas e fechadas que versassem sobre a compreensão dos coordenadores quanto à utilidade dos objetivos do componente Libras no processo ensinoaprendizagem nas IES.

Em seguida, e após convite, os 24 coordenadores dos cursos das IES que ofertam a Libras em seus projetos pedagógicos responderam o questionário produzido pelos pesquisadores.

Os coordenadores foram identificados pelas iniciais do curso (E - Enfermagem; F - Fisioterapia, O Odontologia) seguidas do número sequencial de coleta. Cada curso também foi identificado com essas mesmas letras, seguidas de um numeral crescente. Exemplo: E1... E16; F1... F10; e O1... O4.

O processo de análise fundamentou-se na análise de conteúdo temática (Bardin, 2004), que consiste em três etapas:

1) Pré-Análise - Realizou-se uma leitura flutuante dos projetos pedagógicos em que foram identificadas as unidades de registros que permitiram a delimitação de unidades de codificação e a padronização dos elementos de interesse para o estudo.

2) Exploração do Material - Nesta fase, procedeu-se à releitura do material, em associação com o uso de técnicas como: fichamento, levantamento quantitativo e qualitativo de termos e assuntos recorrentes, e foram criados códigos para facilitar o controle e o manuseio do material. Dessas ações 
resultaram os Quadros 1 a 3 (Adequação dos projetos pedagógicos às suas respectivas Diretrizes Curriculares Nacionais, Distribuição dos cursos por instituição e oferecimento do componente curricular Libras e Perfil do componente curricular Libras nos cursos de Enfermagem, Fisioterapia e Odontologia da Paraíba, respectivamente).

A relação entre a ementa do componente Libras, constante nos 24 projetos, e os dados informados pelos coordenadores dos cursos possibilitou a elaboração do Quadro 4. Categorias emergidas da relação entre as ementas e os objetivos do componente Libras nos cursos.

Da padronização obtida com a exploração do material, emergiram quatro categorias temáticas: C1) $^{2}$ Compreensão cultural na construção da relação profissional/paciente; C2) Legislação aplicada: bases para atuação profissional; C3) Libras nas ciências da saúde: uma prática aplicada; e C4) Libras: uma nova língua, uma nova estrutura.

Quadro 1. Adequação dos projetos pedagógicos às suas respectivas Diretrizes Curriculares Nacionais

\begin{tabular}{|c|c|}
\hline $\begin{array}{c}\text { Recomendações das DCNs para o perfil de egressos nos projetos pedagógicos } \\
\text { dos cursos de Enfermagem, Fisioterapia e Odontologia }\end{array}$ & Cursos com DCN em comum \\
\hline \multicolumn{2}{|l|}{ Comum às três DCNs } \\
\hline Formação generalista, humanista, crítica e reflexiva. & 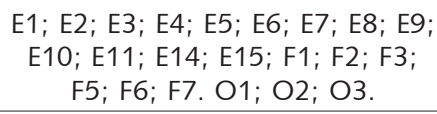 \\
\hline \multicolumn{2}{|l|}{ Enfermagem } \\
\hline $\begin{array}{l}\text { Profissional qualificado para o exercício de Enfermagem com base no rigor científico } \\
\text { e intelectual. }\end{array}$ & $\begin{array}{l}\text { E1; E2; E3; E4; E5; E6; E10; E11; } \\
\text { E12;E13;E14; E15. }\end{array}$ \\
\hline Pautado em princípios éticos. & E4; E5; E7; E10; E11; E14; E15. \\
\hline $\begin{array}{l}\text { Capaz de conhecer e intervir sobre os problemas/situações de saúde/doença mais } \\
\text { prevalentes no perfil epidemiológico nacional, com ênfase na sua região de atuação, } \\
\text { identificando as dimensões biopsicossociais dos seus determinantes. }\end{array}$ & E4; E11; E12; E14. \\
\hline $\begin{array}{l}\text { Capacitado a atuar com senso de responsabilidade social e compromisso com a } \\
\text { cidadania, como promotor da saúde integral do ser humano. }\end{array}$ & $\begin{array}{l}\mathrm{E} 4 ; \mathrm{E6} ; \mathrm{E7} ; \mathrm{E} 11 ; \mathrm{E} 12 ; \mathrm{E} 13 ; \mathrm{E} 14 ; \\
\mathrm{E} 15 .\end{array}$ \\
\hline Capacitado para atuar na Educação Básica e na Educação Profissional em Enfermagem. * & - \\
\hline \multicolumn{2}{|l|}{ Fisioterapia } \\
\hline $\begin{array}{l}\text { Visão ampla e global, respeitando os princípios éticos/bioéticos e culturais do indivíduo } \\
\text { e da coletividade. }\end{array}$ & F2; F7. \\
\hline $\begin{array}{l}\text { Capaz de ter como objeto de estudo o movimento humano em todas as suas formas } \\
\text { de expressão e potencialidades, quer nas alterações patológicas, cinético-funcionais, } \\
\text { quer nas suas repercussões psíquicas e orgânicas, objetivando preservar, desenvolver, } \\
\text { restaurar a integridade de órgãos, sistemas e funções, desde a elaboração do } \\
\text { diagnóstico físico e funcional, eleição e execução dos procedimentos fisioterapêuticos } \\
\text { pertinentes a cada situação. }\end{array}$ & F2; F7. \\
\hline \multicolumn{2}{|l|}{ Odontologia } \\
\hline Capacitado ao exercício de atividades referentes à saúde bucal da população. & O3. \\
\hline Pautado em princípios éticos, legais. & 01; O3. \\
\hline $\begin{array}{l}\text { Compreensão da realidade social, cultural e econômica do seu meio, dirigindo sua } \\
\text { atuação para a transformação da realidade em benefício da sociedade. }\end{array}$ & O1. \\
\hline
\end{tabular}

*Para cursos de licenciatura. 
Quadro 2. Distribuição dos cursos por instituição e oferecimento do componente curricular LIBRAS

\begin{tabular}{|c|c|c|c|c|}
\hline Codificação & Curso & Situação da IES & Titulação & Oferecimento de LIBRAS - Início \\
\hline E1 & Enfermagem & Privada & Bacharelado & Sim - 2011 \\
\hline E2 & Enfermagem & Privada & Bacharelado & Sim - 2011 \\
\hline E3 & Enfermagem & Privada & Bacharelado & Não \\
\hline E4 & Enfermagem & Pública & Bacharelado e licenciatura & Não \\
\hline E5 & Enfermagem & Privada & Bacharelado & Sim -2010 \\
\hline E6 & Enfermagem & Privada & Bacharelado & Sim -2009 \\
\hline E7 & Enfermagem & Privada & Bacharelado & Sim - 2011 \\
\hline E8 & Enfermagem & Privada & Bacharelado & Sim -2010 \\
\hline E9 & Enfermagem & Pública & Bacharelado e licenciatura & Não \\
\hline E10 & Enfermagem & Privada & Bacharelado & Sim -2009 \\
\hline E11 & Enfermagem & Privada & Bacharelado & Sim - 2006 \\
\hline E12 & Enfermagem & Privada & Bacharelado & Sim -2010 \\
\hline E13 & Enfermagem & Pública & Bacharelado & Não - 2012 (previsão) \\
\hline E14 & Enfermagem & Privada & Bacharelado & Não \\
\hline F1 & Fisioterapia & Pública & Bacharelado & Sim - 2011 \\
\hline $\mathrm{F} 2$ & Fisioterapia & Privada & Bacharelado & Sim - 2011 \\
\hline F3 & Fisioterapia & Pública & Bacharelado & Não \\
\hline F4 & Fisioterapia & Privada & Bacharelado & Sim - 2007 \\
\hline F5 & Fisioterapia & Privada & Bacharelado & Não \\
\hline F6 & Fisioterapia & Privada & Bacharelado & Sim - 2010 \\
\hline F7 & Fisioterapia & Privada & Bacharelado & Sim - 2010 \\
\hline O1 & Odontologia & Pública & Bacharelado & Não \\
\hline $\mathrm{O} 2$ & Odontologia & Pública & Bacharelado & Não \\
\hline $\mathrm{O3}$ & Odontologia & Privada & Bacharelado & Sim - 2009 \\
\hline
\end{tabular}

3) Tratamento dos Resultados Obtidos e Interpretação - Nesta fase, as categorias foram analisadas e interpretadas em confronto com os resultados obtidos em outros estudos, por outros pesquisadores.

O estudo seguiu a Resolução 196/96 do Conselho Nacional de Saúde. Portanto, assegurou-se o anonimato das instituições e sujeitos colaboradores, além de se garantir ao informante a participação voluntária, após instrução sobre o objetivo da pesquisa e assinatura do Termo de Consentimento Livre e Esclarecido em duas vias.

\section{Resultados}

$\mathrm{Na}$ análise dos projetos pedagógicos, observou-se a adequação às respectivas Diretrizes Curriculares Nacionais no tocante ao perfil de egressos dos cursos de Enfermagem, Fisioterapia e Odontologia, como disposto no Quadro 1.

No Quadro 2, observa-se a classificação dos cursos quanto ao tipo, situação, titulação e oferta do componente curricular Libras. Desse modo, participaram do estudo: 14 cursos de Enfermagem, sete de 
Quadro 3. Perfil do componente curricular LIBRAS nos cursos de Enfermagem, Fisioterapia e Odontologia da Paraíba; ${ }^{*} \mathrm{C}=$ codificação dos coordenadores

\begin{tabular}{|c|c|c|c|}
\hline C $^{*}$ & Semestre & Classificação do componente curricular & Carga horária \\
\hline E2 & A partir do ${ }^{\circ}$ & Optativo & $60 \mathrm{~h}$ \\
\hline E5 & Qualquer um & Optativo & $40 \mathrm{~h}$ \\
\hline E6 & $7^{\circ}$ e $8^{\circ}$ & Optativo & $60 \mathrm{~h}$ \\
\hline E7 & $8^{\circ}$ & Não respondido & $45 \mathrm{~h}$ \\
\hline E8 & $2^{\circ}$ & Optativo & $40 \mathrm{~h}$ \\
\hline E10 & $2^{\circ}$ & Complementar & $40 \mathrm{~h}$ \\
\hline E11 & Qualquer um & Optativo & $40 \mathrm{~h}$ \\
\hline E12 & Qualquer um & Optativo & $40 \mathrm{~h}$ \\
\hline F1 & Qualquer um & Optativo & $54 \mathrm{~h}$ \\
\hline F2 & Qualquer um & Optativo & $22 \mathrm{~h}$ \\
\hline F4 & $3^{\circ}$ & Optativo & $40 \mathrm{~h}$ \\
\hline F6 & $4^{\circ}$ & Optativo & $60 \mathrm{~h}$ \\
\hline F7 & - & Optativo & \\
\hline O3 & Qualquer um & Optativo & \\
\hline
\end{tabular}

Quadro 4. Categorias emergidas da relação entre as ementas e os objetivos do componente LIBRAS nos cursos

\begin{tabular}{|l|c|}
\hline \multicolumn{1}{|c|}{$\begin{array}{c}\text { Categorias expressivas da relação entre as ementas e os objetivos do } \\
\text { componente libras }\end{array}$} & Cursos \\
\hline (C1) Compreensão cultural na construção da relação profissional/paciente & E5; E6; E7; E8; E10; E11; F2; F4; F6; O3. \\
\hline (C2) Legislação aplicada: bases para atuação profissional & E8. \\
\hline (C3) LIBRAS nas ciências da saúde: uma prática aplicada & E6; E7; E8; E10; E11; F4; O3. \\
\hline (C4) LIBRAS: uma nova língua, uma nova estrutura
\end{tabular}

Fisioterapia e três de Odontologia. Destaca-se que este componente não é ofertado por nove cursos, sendo seis de IES públicas e três de instituições privadas.

Em relação aos cursos de Enfermagem, 11 são de instituições privadas e três são de públicas. A maioria deles $(n=8)$ oferece o componente curricular Libras. Já os cursos de Fisioterapia, cinco são de instituições privadas e dois são de públicas, dentre os quais, cinco oferecem esse componente curricular. Quanto aos cursos de Odontologia, um é de instituição privada e dois são de públicas, e somente um oferece a Libras. Dentre as IES pesquisadas, apenas duas (E4, E9) possuem o curso de licenciatura, ambas são públicas e o componente curricular Libras não está sendo oferecido.

Os cursos E11 e F4 oferecem o componente curricular Libras desde 2006 e 2007, respectivamente. Além da Libras inserida na matriz do currículo, o E10 tem um projeto de extensão em relação à Libras em um hospital público de João Pessoa; e o E11 oferece, aos alunos, inserção em um centro de referência para o atendimento em saúde de pessoas surdas na capital do estado.

Os coordenadores dos cursos E2, E7 e F2 responderam que o componente Libras já consta no currículo, entretanto ainda não foi disponibilizado aos estudantes. Os demais cursos ( $n=12)$ incluíram a Libras no currículo a partir de 2009. 
No Quadro 3, são destacadas as características do componente curricular Libras dos cursos ( $n=14)$, indicando-se: curso, disponibilidade semestral do componente, classificação e carga horária.

Os coordenadores dos cursos E8, E10, E11, E12, F2, F4 e F6 citaram a vinculação de professor qualificado com especialização e experiência na interpretação da Libras; o coordenador de O3 afirmou a qualificação de mestre de seus docentes. Esses docentes desenvolvem atividades acadêmicas e pedagógicas, atuando como facilitadores do processo ensino-aprendizagem desse componente.

Neste estudo foi encontrado um quantitativo expressivo (58\%) de oferecimento da Libras como componente curricular optativo entre as IES pesquisadas, com cargas horárias que variaram de 22 a 60 horas, bem como ementas que tratam dos aspectos cultural, legal, linguístico, prático, e com aplicações ao atendimento em saúde. Porém, essa realidade seguia paralela a respostas imprecisas quanto à organização do componente, formação do profissional de Libras e suas atribuições.

Em relatos dos coordenadores cujos cursos ofereceram a Libras a partir de 2010, registrados em diários de campo, constatou-se ainda que a "exigência" do MEC foi condição determinante para a implantação ágil do componente no currículo dos cursos de saúde.

Os conteúdos das ementas investigadas abordam temas como: a cultura da comunidade surda, a Libras e sua estrutura linguística, a abordagem prática de comunicação, política e legislações inclusivas.

No Quadro 4, constam as categorias temáticas emergentes da relação entre a ementa do componente Libras e o objetivo do processo ensino-aprendizagem da Libras informado pelos coordenadores, destacando-se os cursos em que houve essa relação.

\section{Discussão}

No Quadro 1, a "Formação generalista, humanista, crítica e reflexiva" apareceu como recomendação das DCNs comum aos projetos pedagógicos dos cursos estudados. Outrossim, a graduação em Enfermagem destacou-se como o curso de maior consenso em relação à inserção das DCNs no perfil do egresso.

A constatação supracitada é relevante, pois, a partir de 2001, as DCNs dos cursos de graduação em saúde indicaram novos caminhos e estratégias para inovar e transformar a orientação e organização dos cursos, correspondendo às necessidades reconhecidas como relevantes ao SUS e à população (Ceccim, Feuerwerker, 2004). Afirma-se que a formação do profissional de saúde deve contemplar o sistema de saúde vigente no país, o trabalho em equipe e a atenção integral à saúde (Brasil, 2002a, 2002b, 2001).

Em relação aos cursos de Enfermagem, Odontologia e Fisioterapia, as DCNs expõem, no art. $4^{\circ}$, que, na interação com outros profissionais de saúde e o público em geral, os profissionais devem ser acessíveis, lançando mão de um processo de comunicação verbal, não verbal e/ou habilidades de escrita e leitura; além do domínio de tecnologias de comunicação e informação, e de manter a confidencialidade das informações recebidas (Brasil, 2002a, 2002b, 2001).

No entanto, as DCNs constituem apenas uma recomendação, já que, no Brasil, as universidades têm autonomia, definida, na Lei de Diretrizes e Bases da Educação Nacional (LDB), como prerrogativa de criação, expansão e modificação de cursos e programas de Educação Superior, e, também, de fixação dos currículos de seus cursos e programas. Nesse sentido, acredita-se que o processo de aproximação e construção de compromissos entre a universidade e os serviços/sistema de saúde favoreça a ampliação da responsabilidade pública e da relevância social da universidade (Ceccim, Feuerwerker, 2004).

Gonzalez e Almeida (2010) recomendam enxergar a realidade além dos limites disciplinares e conceituais do conhecimento. Ito et al. (2006) ressaltam a necessidade do compromisso da Educação Superior com a formação de profissionais competentes, crítico-reflexivos e de cidadãos que possam atuar não apenas em sua área de formação, mas também no processo de transformação da sociedade.

Relativamente à formação dos profissionais, as DCNs abrem a possibilidade de as IES definirem diferentes perfis de seus egressos e adaptarem esses perfis às transformações das ciências contemporâneas e às necessidades sociopolítico-econômicas da sociedade (Ito et al., 2006). A construção de um novo modelo pedagógico deve ter como perspectiva o equilíbrio entre excelência técnica e relevância social, como princípios para nortear o movimento de mudança, que deve estar 
sustentado: na integração curricular, em modelos pedagógicos mais interativos, na adoção de metodologias de ensino-aprendizagem centradas no aluno como sujeito da aprendizagem, e no professor como facilitador do processo de construção de conhecimento (Campos, 2001; Feuerwerker, Sena, 1999).

No concernente à oferta do componente curricular Libras apresentada no Quadro 2, destaca-se o crescente interesse das instituições em disponibilizá-lo aos alunos. Essa prática corrobora com a opinião de Souza e Pozzori (2009), que ratificam a importância da formação em Libras para os profissionais de saúde, citando experiências de cidades que oferecem esse tipo de capacitação para seus profissionais. E mostram que há grande relevância tanto no âmbito do relacionamento interpessoal com os usuários, imperativo nas relações de cuidado/atendimento em saúde, quanto no aprimoramento da nova língua que aprenderam, uma vez que a língua dos sinais necessita de prática e desenvolvimento, aumentando, assim, a capacidade de comunicação entre seus usuários (Souza, Pozzori, 2009).

Por outro lado, foi preocupante a constatação da lacuna do oferecimento de Libras nos cursos de licenciatura de instituições públicas, pois, além de os profissionais formados necessitarem de tal conhecimento em sua prática, esse dado descumpre o Decreto $n^{\circ} 5.626 / 05$, que recomenda a inserção da Libras como componente curricular obrigatório nos cursos de formação de professores para o exercício do magistério, em nível médio e superior.

Diante do oferecimento da Libras posto como compulsório em alguns cursos, é necessário salientar que a qualificação do professor de Libras é muito importante, pois tal componente curricular exige do profissional a fluência na língua de sinais. E, no caso do Brasil, da língua portuguesa, para que as mesmas tenham concordância, prestígio e rigor. Porém, devido aos poucos profissionais na área, torna-se difícil o cumprimento da legislação e a formação de educadores e profissionais bilíngues (Martins, 2008).

No Quadro 2, observou-se que a desproporção quanto à oferta do componente Libras entre as instituições públicas e privadas demonstra que as instituições privadas estão mais atentas às recomendações do Decreto $n^{\circ}$ 5.626/05 do que as instituições públicas inseridas nesta investigação.

O desinteresse nesse tipo de formação, verificado no estudo de Souza e Pozzori (2009), indica a não-existência de uma disposição reflexiva sobre o tema, tampouco preocupação com a realidade social. Nesse sentido, as ementas do componente curricular Libras deveriam permitir uma aprendizagem concreta da língua e sua aplicação no âmbito profissional.

Autores relatam que o ensino de Libras tem baixo status porque não existem sistematização e avaliação do processo de ensino-aprendizagem, não há conteúdos definidos por série, nem a exigência de avaliação que permita diagnosticar o nível de aprendizagem e desenvolvimento da Libras por parte dos alunos (Cavalcante et al., 2004).

A Libras é uma língua, portanto aprendê-la vai além do momento em sala de aula, exigindo um contexto e contato com a cultura em questão. Nesse aspecto, Martins (2008) frisa que é preciso cuidado, tanto por parte do MEC como das IES, para que o ensino da Libras não se torne superficial. Entende-se que a inserção da Libras deve buscar promover uma aproximação maior com o tema e discussões entre discentes e docentes da área da saúde, sensibilizando-os a rever suas práticas de cuidado, para a promoção da integralidade e humanização na assistência aos surdos.

Assim, para atenderem às recomendações dos perfis desejados e poderem realizar um atendimento integral, Souza e Porozzi (2009) trazem como elementar que os profissionais da saúde sejam capazes de se comunicar de maneira eficiente com os usuários surdos, dando ainda um destaque para aqueles que atuam na Atenção Básica. Isso poderia ser viabilizado, inicialmente, pela inclusão e fortalecimento do componente Libras para todos os cursos, com obrigação legal de disponibilizá-lo, sendo a oferta desse componente no próprio currículo um importante passo para um melhor atendimento desse tipo de usuário.

Em seu estudo, Souza e Pozzori (2009) apontam quão é importante os cursos de saúde terem uma visão mais acolhedora na implantação do componente Libras em seus currículos, sugerindo até que, a médio e longo prazo, o referido componente se torne obrigatório em todos os cursos da área de saúde. Tal opinião se embasa na não-atração que esse componente curricular, como optativo, provoca nos estudantes, que podem não ter noção da importância do mesmo em suas vidas profissionais. 
$\mathrm{Na}$ análise da categoria Compreensão cultural na construção da relação profissional/paciente, destacam-se os seguintes trechos extraídos das ementas:

\author{
"Aspecto histórico da comunidade surda, aspectos clínicos, educacionais e sócio- \\ antropológicos da surdez." (E11) \\ "Posicionamento crítico e interativo quanto à importância da utilização da Libras no \\ atendimento às pessoas surdas." (F4) \\ "[...] estudo da língua de sinais, para a comunicação no cotidiano com o surdo." (O3)
}

Esses recortes, representativos da maioria das ementas dos cursos investigados, focam a atuação direta do profissional para com o paciente, compreendendo seu contexto biológico, social e cultural.

Para Santos (2003), uma instituição educacional ressignificada dentro do paradigma inclusivo necessita compreender que não é a quantidade de conteúdos que garante uma boa formação, mas, sim, todo um conjunto de fatores: pedagógicos, culturais e sociais. Nessa perspectiva, as ementas coletadas apresentam a preocupação das IES em contextualizar o tema em questão, bem como de contribuir para o entendimento da cultura dos surdos.

Em seu estudo, Santos e Shiratori (2004) desvelam as necessidades de saúde da comunidade surda e revelam a comunicação como a maior barreira enfrentada por estes usuários em serviços de saúde. Segundo seus entrevistados, o estabelecimento da comunicação profissional/paciente facilitaria bastante o esclarecimento de suas dúvidas durante o atendimento.

Salienta-se que o acesso ainda é um problema que vem sendo enfrentado na implantação plena e no funcionamento de serviços de saúde, pois algumas barreiras dificultam a entrada do usuário na atenção à saúde. No caso da comunidade surda, a barreira de comunicação com profissionais não conhecedores da Libras influi diretamente na utilização dos serviços e na resolução dos problemas (Freire et al., 2009).

Nesse sentido, Santos e Shiratori (2004) evidenciam que o entendimento do contexto social e de vida do surdo, bem como o relacionamento com o profissional de saúde ficam extremamente comprometidos, devido à não-construção de "elos" acarretada pelo despreparo dos serviços e profissionais de saúde para atender esta clientela.

Em relação à categoria Legislação aplicada: bases para atuação profissional, as ementas expressaram:

“Lei 8.213/91 e o acesso do surdo ao trabalho." (E6)

"[...] conscientizando os alunos sobre o uso da Libras sobre responsabilidade social de atender os surdos em Libras de acordo com a legislação vigente." (E7)

Os recortes possibilitam a compreensão de que os cursos reconhecem a utilidade prática da Libras nos serviços de saúde; e, ao citarem a Lei 8.213/91, demonstraram-se conhecedores dos benefícios do auxílio-doença, estabilidade no emprego, aposentadoria e regime de previdência social que essa lei assegura aos surdos. Entretanto, apenas o coordenador do curso E8 afirmou a abordagem de legislações inclusivas nos objetivos do componente Libras de seu curso.

As normas em defesa de mais inclusão das pessoas surdas vêm sendo publicadas e devem ser de conhecimento geral. Assim, as IES precisam se preocupar com o conhecimento das leis e portarias que norteiam a formação do profissional de saúde, que garantem a inclusão social da comunidade surda e o direito dos surdos a uma comunicação eficiente nos serviços de saúde.

O conhecimento dessas peças jurídicas é importante, pois a barreira de comunicação afeta o cuidado em saúde, desde o acesso ao atendimento clínico, comprometendo, sobretudo, a formação de vínculo profissional/usuário, colocando em risco a assistência integral (Chaveiro, Barbosa, Porto, 2008). 
Nesse sentido, a categoria Libras nas ciências da saúde: uma prática aplicada enfoca a valorização atribuída pelos cursos ao uso da Libras pelos profissionais de saúde:

"A aprendizagem, compreensão, análise e uso da língua de sinais brasileira e os movimentos do corpo e mãos envolvidos em cada sinal." (F7)

"Recepção e emissão da língua de sinais." (O3)

"[...] sinais específicos para trabalho." (E11)

Os recortes expressam a preocupação com a aprendizagem dos sinais da Libras próprios para atuação no trabalho, refletindo a importância da comunicação eficaz entre profissionais de saúde e a pessoa surda.

Sendo a Libras uma língua de expressão de natureza visual-motora, com estrutura gramatical própria, faz-se necessário um entendimento prático de sinais do seu sistema linguístico para transmissão de ideias e fatos (Brasil, 2002c).

Essa necessidade também é citada por Cardoso, Rodrigues e Bachion (2006), quando afirmam que a tentativa de comunicação dos profissionais de saúde com essa clientela se dá por meio de formas rudimentares e, frequentemente, há necessidade de que um acompanhante esteja presente para fazer a intermediação.

Outro ator de destaque neste processo de intermediação entre pessoas surdas e os profissionais de saúde são os tradutores/intérpretes de Libras, que se comunicam com os pacientes surdos e buscam repassar as informações da maneira mais precisa, evitando a presença de uma terceira pessoa que não seja profissional. Esses profissionais podem minimizar as dificuldades enfrentadas pelos surdos, os quais apresentam necessidades específicas e, por isso, encontram barreiras para participar plenamente de várias atividades sociais regulares, devido ao obstáculo da comunicação (Olah, Olah, 2010).

Todavia, existem algumas críticas e limitações para a atuação dos intérpretes. Sua presença durante o atendimento pode aumentar o constrangimento, colocar maior risco ao direito de sigilo e privacidade, bem como à qualidade das informações repassadas (Chaveiro et al., 2010), já que na saúde há conhecimentos e uma linguagem técnica específicos da área, e que podem ser desconhecidos pelo intérprete, comprometendo a transmissão da informação ao paciente. Outra crítica à participação de intérpretes está relacionada com o estabelecimento dos vínculos. Freire et al. (2009) destacam a dificuldade de formação de vínculo profissional/usuário quando não se estabelece a comunicação direta entre os mesmos.

Uma estratégia para minimizar tal problemática pode ser o estabelecimento de sinais padronizados. Souza e Pozzori (2009) ressaltam a necessidade da Libras no âmbito da saúde para popularizar e padronizar sinais específicos e passíveis de identificação pelo surdo. Citam ainda que novas palavras estão sendo incorporadas no dicionário de Libras, através da criação de uma apostila com sinais específicos apropriados referentes à área da saúde.

Portanto, a utilização da Libras deve tornar-se uma prática aplicada, pois os profissionais da saúde relatam que não se sentem preparados para atender pacientes surdos por não conseguirem estabelecer uma comunicação efetiva, fator que causa desconforto tanto aos profissionais quanto aos pacientes (Oliveira, Lopes, Pinto, 2009; Pagliuca, Fiúza, Rebouças, 2007).

Assim, no caso específico do surdo e da assistência em saúde, acredita-se que a capacitação de recursos humanos para estabelecer uma comunicação eficaz com esse paciente possibilita que o profissional entenda as suas necessidades, compreenda-o como ser holístico e preste assistência adequada, minimizando seu sofrimento (Pagliuca, Fiúza, Rebouças, 2007). Nesse contexto, é importante que haja um entendimento, por parte de estudantes e profissionais, sobre a importância de se estudar Libras como língua que pode melhorar sua atuação laboral.

Além de reconhecer a relevância da Libras para a assistência em saúde, na categoria Libras: uma nova língua, uma nova estrutura, as ementas destacaram as características da estrutura da Libras: 
“[...] morfologia da língua de sinais, datilologia e alfabeto manual. O nome próprio [...] Libras em contexto versus língua portuguesa falada e escrita. [...] partículas de negação e textos para interpretação." (E6)

“[...] estrutura gramatical; análise textual [...]; sinais gerais; tempo; verbos; substantivos, adjetivos." (E11)

"Aspectos fonológicos, morfológicos e sintáticos da língua de sinais brasileira."

Como relata Martins (2008), ainda há uma incompreensão sobre o reconhecimento da Libras como a língua oficial da comunidade surda. Ela possui uma estrutura diferente dos padrões tradicionais e clássicos da linguística. A compreensão dessa estrutura foi uma citação unânime nas ementas estudadas, evidenciando a importância dada ao conhecimento da construção do signo (significante e significado) na composição verbal e gramatical próprias da língua, porém em apenas três cursos (E5; E6; E7) os objetivos corroboram as ementas.

Dessa forma, considerando o momento de incorporação da Libras no currículo dos profissionais de saúde, é importante que haja uma constante avaliação de como está se dando seu planejamento e implantação, devido à necessidade da formação de profissionais com visão integral do cuidado em saúde, inclusive para a comunidade surda, compreendendo seu contexto social, conhecendo a legislação vigente e estabelecendo uma comunicação eficiente para a construção do vínculo profissional/paciente.

\section{Considerações finais}

A comunicação é um processo de interação no qual se compartilham mensagens, ideias, sentimentos e emoções. Na assistência em saúde, somente a partir de uma boa comunicação estabelecida se poderão identificar e resolver as necessidades dos pacientes de forma humanizada e integral.

Constatou-se que as instituições, especialmente as privadas, têm buscado atender à determinação legal e às recomendações do MEC quanto à adequação da matriz curricular dos projetos pedagógicos, inserindo a Libras como componente optativo, para atender ao perfil de profissionais humanistas, críticos e com uma atuação inclusiva.

A adoção do componente curricular Libras, por meio da elaboração de ementas e conteúdos com ênfase na inclusão social de pessoas surdas, aliada à contratação de profissionais qualificados em Língua de Sinais, foram observadas como parâmetros para as ações educativas e inclusivas das instituições. Desse modo, nessas instituições, a formação dos profissionais de saúde contribui para o atendimento integral e equânime a todos os cidadãos.

Contudo, observou-se que as instituições com cursos de licenciatura relataram não haver previsão de cumprimento da lei que estabelece a obrigatoriedade do componente curricular Libras. Tal fator é preocupante, pois tais instituições também estão formando educadores, e a ausência de discussão acerca desse tema pode afetar negativamente o desenvolvimento de competências e habilidades profissionais comprometidas com a realidade social, com vistas a uma prática humanizada, acolhedora e integral. Além de retardar o processo que amplia a inclusão de pessoas surdas também na área da educação.

O processo de mudança na formação do profissional de saúde ainda precisa ser acompanhado e avaliado, portanto sugere-se investigar a percepção dos estudantes (surdos ou não) sobre a discussão da inclusão social das pessoas e da cultura dos surdos. E a realização de outros estudos na área, objetivando avaliar a qualidade da oferta do componente Libras, para tornar efetiva e eficiente a contribuição desse novo e importante conhecimento para os profissionais de saúde. 


\section{Colaboradores}

As autoras Yanik Carla Araújo de Oliveira e Renata de Oliveira Cartaxo responsabilizaram-se por: coleta de dados, análise, escrita e aprovação final do artigo. Os autores Alexsandro Silva Coura, Gabriela Maria Cavalcanti Costa e Inacia Sátiro Xavier de França responsabilizaram-se por: concepção, desenho, revisão crítica e aprovação final do artigo.

\section{Referências}

BARDIN, L. Análise de conteúdo. Trad. Luís Antero Reto e Augusto Pinheiro. Lisboa: Edições 70, 2004.

BRASIL. Subchefia para Assuntos Jurídicos. Decreto $n^{\circ} 5.626$, de 22 de dezembro de 2005. Regulamenta a Lei no 10.436, de 24 de abril de 2002, que dispõe sobre a Língua Brasileira de Sinais - Libras, e o art. 18 da Lei n 10.098, de 19 de dezembro de 2000. Brasília: Ministério da Justiça, 2005.

Conselho Nacional de Educação. Câmara de Educação Superior. Resolução CNE/CES no 3, de 19 de fevereiro de 2002. Institui Diretrizes Curriculares Nacionais do Curso de Graduação em Odontologia. Brasília: Ministério da Educação, 2002a.

Conselho Nacional de Educação. Câmara de Educação Superior. Resolução CNE/CES no 4, de 19 de fevereiro de 2002. Institui Diretrizes Curriculares Nacionais do Curso de Graduação em Fisioterapia. Brasília: Ministério da Educação, 2002b.

Subchefia para Assuntos Jurídicos. Lei no 10.436 de 24 de abril de 2002. Dispõe sobre a Língua Brasileira de Sinais - Libras e dá outras providências. Brasília: Ministério da Justiça, 2002c.

Conselho Nacional de Educação. Câmara de Educação Superior. Resolução CNE/CES n' 3, de 7 de novembro de 2001. Institui Diretrizes Curriculares Nacionais do Curso de Graduação em Enfermagem. Brasília: Ministério da Educação, 2001.

CAMPOS, F.E. et al. Caminhos para Aproximar a Formação de Profissionais de Saúde das Necessidades da Atenção Básica. Rev. Bras. Educ. Méd., v.25, n.2, p.53-9, 2001

CARDOSO, A.H.A; RODRIGUES, K.G; BACHION, M.M. Perception of persons with severe or profound deafness about the communication process during health care. Rev. Latinoam. Enferm., v.14, n.4, p.553-60, 2006.

CAVALCANTE, K.S. et al. Elaborando Proposta Curricular para o Ensino de Libras e Língua Portuguesa no Ensino de Surdos. In: CONGRESSO BRASILEIRO DE EXTENSÃO UNIVERSITÁRIA, 2., 2004, Belo Horizonte. Anais... Belo Horizonte: 2004. Disponível em: <https://www.ufmg.br/congrext/Educa/Educa77.pdf>. Acesso em: 18 jul. 2011.

CECCIM, R.B.; FEUERWERKER, L.C.M. Mudança na graduação das profissões de saúde sob o eixo da integralidade. Cad. Saude Publica, v.20, n.5, p.1400-10, 2004.

CHAVEIRO, N. et al. Atendimento à pessoa surda que utiliza a Língua de Sinais, na perspectiva dos profissionais da saúde. Cogitare Enferm., v.15, n.4, p.639-45, 2010

CHAVEIRO, N.; BARBOSA, M.A.; PORTO, C.C. Revisão de literatura sobre o atendimento ao paciente surdo pelos profissionais da saúde. Rev. Esc. Enferm. USP, v.42, n.3, p.578-83, 2008

DESLANDES, S.F.; MITRE, R.M.A. Processo comunicativo e humanização em saúde. Interface - Comun. Saude Educ., v.13, supl.1, p.641-9, 2011. Disponível em: <http:// www.scielo.br/scielo.php?script $=$ sci_arttext $\&$ pid $=$ S1414-32832009000500015 $\& \operatorname{lng}=$ en\&nrm=iso $>$. Acesso: 3 jul. 2011. 
FEUERWERKER, L.C.M.; SENA, R.R. A construção de novos modelos acadêmicos, de atenção à saúde e de participação social. In: ALMEIDA, M.; FEUERWERKER, L.L. (Orgs.). A educação dos profissionais de saúde na América Latina: teoria e prática de um movimento de mudança. São Paulo: Hucitec, 1999. p.47-82.

FREIRE, D.B. et al. Acesso de pessoas deficientes auditivas a serviços de saúde em cidade do Sul do Brasil. Cad. Saude Publica, v.25, n.4, p.889-97, 2009.

GONZALEZ, A.D.; ALMEIDA, M.J. Integralidade da saúde: norteando mudanças na graduação dos novos profissionais. Cienc. Saude Colet., v.15, n.3, p.757-62, 2010.

INSTITUTO BRASILEIRO DE GEOGRAFIA E ESTATÍSTICA (IBGE). Censo Demográfico Brasileiro 2010: características gerais da população, religião e pessoas com deficiência. Disponível em: <ftp://ftp.ibge.gov.br/Censos/Censo_Demografico_2010/

Caracteristicas_Gerais_Religiao_Deficiencia/caracteristicas_religiao_deficiencia.pdf $>$. Acesso em: 30 mar. 2012.

ITO, E.E. et al. O ensino de enfermagem e as diretrizes curriculares nacionais: utopia $\mathrm{X}$ realidade. Rev. Esc. Enferm. USP, v.40, n.4, p.570-5, 2006.

MARTINS, V.R.O. Análise das vantagens e desvantagens da Libras como disciplina curricular no ensino Superior. Rev. Cad. CEOM, v.21, n.28, p.191-206, 2008.

OLAH, L.V.A.S; OLAH, N.C.S. O intérprete de Libras e a inclusão social do surdo. Rev. Pandora Brasil, v.24, n.24, p.1-15, 2010.

OLIVEIRA, D.C. Análise de conteúdo temático-categorial: uma proposta de sistematização. Rev. Enferm. UERJ, v.16, n.4, p.569-76, 2008.

OLIVEIRA, H.R.; LOPES, K.S.; PINTO, N.M.M. Percepção da equipe de enfermagem acerca da assistência prestada ao deficiente auditivo. Rev. Enferm. Integr., v.2, n.1, p.165-75, 2009.

PAGLIUCA, L.M.F.; FIÚZA, N.L.G.; REBOUÇAS, C.B.A. Aspectos da comunicação da enfermeira com o deficiente auditivo. Rev. Esc. Enferm. USP, v.41, n.3, p.411-8, 2007.

QUADROS, R.M. O tradutor e intérprete de língua brasileira de sinais e língua portuguesa. Brasília: MEC-SEESP, 2004.

SACRISTÁN, J.G. O currículo: uma reflexão sobre a prática. Porto Alegre: Artmed, 2000.

SANTOS, M.P. A formação de professores no contexto da inclusão. In: CONGRESSO INTERNACIONAL DO INES, 2., 2003, Rio de Janeiro. Anais ... Rio de Janeiro, 2003. p.63-70.

SANTOS, E.M.; SHIRATORI, K. As necessidades de saúde no mundo do silêncio: um diálogo com os surdos. Rev. Eletron. Enferm., v.6, n.1, p.68-76, 2004.

SILVA, M.J.P. Comunicação tem remédio: a comunicação nas relações interpessoais em saúde. 4.ed. São Paulo: Loyola, 2006.

SOUZA, M.T.; PORROZZI, R. Ensino de libras para os profissionais de saúde: uma necessidade premente. Rev. Práxis, v.1, n.2, p.43-6, 2009. 
OLIVEIRA, Y.C.A. et al. La lengua brasileña de señales en la formación de profesionales de Enfermería, Fisioterapia y Odontología en el estado de Paraiba, Brasil. Interface Comunic., Saude, Educ., v.16, n.43, p.995-1008, out./dez. 2012.

Este trabajo analiza proyectos pedagógicos de graduación de Enfermería, Fisioterapia y Odontología, acerca de la inclusión de Lenguaje de Signos de componentes (LIBRAS) y de los parámetros que rigen esta actividad en la formación de profesionales de salud, asegurando la integridad y humanización de la asistencia. Es un estudio transversal y documental con planteamiento cualitativo realizado en 25 cursos de Paraíba además del análisis de proyectos educativos, 24 coordinadores respondieron a un cuestionario, y los datos analizados de acuerdo con Bardin. Los resultados indican que $58 \%$ de los cursos ofrecen LIBRAS y que para los de licenciatura no está disponible. Los contenidos abarcan temas como cultura de comunidad sorda, LIBRAS y su estructura lingüística, y enfoque práctico de políticas inclusivas de comunicación y legislaciones inclusivas. Esta situación sigue paralela a respuestas vagas con respecto a la organización del componente, la formación profesional en LIBRAS y sus asignaciones.

Palabras clave: Lenguaje de signos. Capacitación de recursos humanos en salud. Enfermería. Odontología. Fisioterapia. 